\title{
Characterization of Physical, Thermal and Spectral Properties of Biofield Treated 2-Aminopyridine
}

\author{
Mahendra Kumar Trivedi ${ }^{1}$, Alice Branton ${ }^{1}$, Dahryn Trivedi ${ }^{1}$, Gopal Nayak ${ }^{1}$, \\ Rakesh Kumar Mishra ${ }^{2}$, Snehasis Jana ${ }^{2, *}$ \\ ${ }^{1}$ Trivedi Global Inc., Henderson, USA \\ ${ }^{2}$ Trivedi Science Research Laboratory Pvt. Ltd., Bhopal, Madhya Pradesh, India
}

Email address:

publication@trivedisrl.com (S. Jana)

\section{To cite this article:}

Mahendra Kumar Trivedi, Alice Branton, Dahryn Trivedi, Gopal Nayak, Rakesh Kumar Mishra, Snehasis Jana. Characterization of Physical, Thermal and Spectral Properties of Biofield Treated 2-Aminopyridine. Science Journal of Analytical Chemistry.

Vol. 3, No. 6, 2015, pp. 127-134. doi: 10.11648/j.sjac.20150306.18

\begin{abstract}
Aminopyridine is an important compound, which is used as intermediate for the synthesis of pharmaceutical compounds. The present work was aimed to assess the effect of Mr. Trivedi's biofield energy treatment on the physical, thermal and spectral characteristics of 2-AP. The work was accomplished by dividing the sample in two parts i.e. one part was remained untreated, and another part had received biofield energy treatment. Subsequently, the samples were analyzed using various characterization techniques such as X-ray diffraction, differential scanning calorimetry, thermogravimetric analysis, ultra violet-visible spectroscopy, and Fourier transform infrared spectroscopy. The XRD analysis revealed a decrease in crystallite size of the treated sample $(91.80 \mathrm{~nm})$ as compared to the control sample $(97.99 \mathrm{~nm})$. Additionally, the result showed

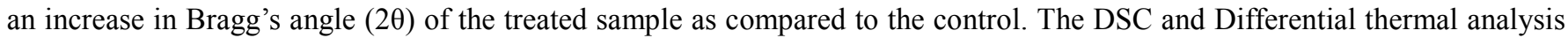
analysis showed an increase in melting temperature of the treated 2-AP with respect to the control. Moreover, the latent heat of fusion of the treated sample was increased by $3.08 \%$. The TGA analysis showed an increase in onset of thermal degradation $\left(\mathrm{T}_{\text {onset }}\right.$ ), and maximum thermal decomposition temperature $\left(\mathrm{T}_{\max }\right)$ of the treated 2-AP as compared to the control sample. Additionally, the treated sample showed a reduction in weight loss as compared with the control indicating higher thermal stability of the sample. UV-visible analysis showed no changes in the absorption peak of the treated sample as compared to the control. The FT-IR spectroscopic results showed downward shifting of C-H stretching vibration $2991 \rightarrow 2955 \mathrm{~cm}^{-1}$ in treated sample with respect to the control.
\end{abstract}

Keywords: Biofield Energy Treatment, 2-Aminopyridine, X-Ray Diffraction, Thermal Analysis

\section{Introduction}

Aminopyridines are an important class of compounds used as a research tool for characterizing subtypes of the potassium channel [1]. 4-Aminopyridine or fampridine is used as a drug for symptomatic treatment of multiple sclerosis and it is believed to improve the walking in adults with several variations of the disease [1, 2]. It acts by blocking the potassium channels and prolong the action potentials, thereby releases neurotransmitters at the neuromuscular junction [3]. 2-Aminopyridine (2-AP) is one of the isomers of aminopyridines and it has been used for the synthesis of pharmaceutical agents [4]. 2-AP is a colourless solid used in the production of piroxicam, which is used as a non-steroidal anti-inflammatory drug (NSAID) to relieve the symptoms of painful, inflammatory conditions like arthritis $[5,6]$. It has been used as an intermediate for the synthesis of pharmaceutical agents such as sulfapyridine, tenoxicam, and tripelennamine [4]. Recently Gonzalez Cabrera et al. [7] and Younis et al. [8, 9] synthesized the 2-AP derivatives as potential anti-malarial candidates, and they evaluated its efficiency in Plasmodium berghei infected mouse model. Dambuza et al. also reported the antimalarial properties of 3,5-Diaryl-2-aminopyridine derivatives [10]. Moreover, 2-AP based compounds have been evaluated for the treatment of Alzheimer's and neuro vascular diseases [11].

Pharmaceutical analysis and stability are required to validate the potency, identity and purity of the ingredients as well as those of the formulated products [12]. The stability of pharmaceutical agents is known as the capability of a 
formulation in a container to remain within its physical, chemical, microbiological, and toxicological specifications [13]. Thus, novel methods should be explored in order to improve the pharmaceutical stability of the drugs. Recently biofield energy treatment was used as a lucrative approach for modification of the physicochemical properties of various materials such as organic compounds [14] drugs [15], and polymers [16].

Biofield energy treatment is a healing technique where life force energy is transmitted to a person's biofield (energy body) by a practitioner. Further, the human biofield is also referred as an energetic field or matrix that surrounds the human body. This energetic field is identical to superhighway that allows the DNA in cells to communicate faster than light and maintain coherent, holistic intelligence in the organism [17]. Thus, it is envisaged that human beings have the ability to harness the energy from the environment/Universe and can transmit into any object (living or non-living) around the Globe. The object(s) will always receive the energy and responding in a useful manner that is called biofield energy. Moreover, biofield energy treatment which comes under the category of Complementary and Alternative Medicine (CAM) therapies have been approved by the prestigious National Institute of Health (NIH)/The National Centre for Complementary and Alternative Medicine (NCCAM), as an alternative treatment in the healthcare sector [18].

Mr. Mahendra Kumar Trivedi is a well-known healer of biofield energy therapy who can alter the characteristics of living and non-living things. The biofield treatment has improved the growth and production of agriculture crops [19] and significantly altered the phenotypic characteristics of various pathogenic microbes [20]. This unique biofield energy treatment is also known as The Trivedi Effect ${ }^{\mathbb{R}}$. Hence, by considering the excellent outcomes from biofield energy treatment and pharmaceutical properties of 2-AP, this research work was undertaken to investigate the impact of biofield energy treatment on the physical, thermal and spectral properties of this compound. The control and treated samples were analysed for their physicochemical properties using various analytical techniques such as X-ray diffraction, differential scanning calorimetry, thermogravimetric analysis, ultra violet-visible spectroscopy analysis, and Fourier transform infrared spectroscopy.

\section{Experimental}

\subsection{Materials}

2-Aminopyridine was procured from S D Fine Chemicals Ltd., India.

\subsection{Methods}

The sample was divided into two parts: control and treated. One part was kept aside as a control sample while the other part was subjected to Mr. Trivedi's biofield energy treatment and labelled as treated sample. The treated group was in sealed pack and handed over to Mr. Trivedi for biofield energy treatment. Mr. Trivedi given the energy treatment through his energy transmission process to the treated group without touching the sample under laboratory conditions.

\subsection{X-Ray Diffraction (XRD)}

XRD analysis of control and treated 2-AP was evaluated using X-ray diffractometer system, Phillips, Holland PW 1710 which consist of a copper anode with nickel filter. XRD system had a radiation of wavelength $1.54056 \AA$. The average crystallite size $(\mathrm{G})$ was computed using formula:

$$
\mathrm{G}=\mathrm{k} \lambda /(\mathrm{b} \operatorname{Cos} \theta)
$$

Here, $\lambda$ is the wavelength of radiation used, $b$ is full-width half-maximum (FWHM) of peaks and $\mathrm{k}$ is the equipment constant.

Percentage change in crystallite size was calculated as:

$$
\left[\left(\mathrm{G}_{\mathrm{t}}-\mathrm{G}_{\mathrm{c}}\right) / \mathrm{G}_{\mathrm{c}}\right] \times 100
$$

Where, $G_{c}$ and $G_{t}$ are denoted as crystallite size of control and treated powder samples, respectively.

\subsection{Differential Scanning Calorimetry (DSC)}

The control and treated 2-AP samples were analyzed using Pyris-6 Perkin Elmer DSC at a heating rate of $10^{\circ} \mathrm{C} / \mathrm{min}$ and the air was purged at a flow rate of $5 \mathrm{~mL} / \mathrm{min}$. The predetermined amount of sample was kept in an aluminum pan and closed with a lid. A reference sample was prepared using a blank aluminum pan. The percentage change in latent heat of fusion was calculated using following equations:

$$
\left[\Delta \mathrm{H}_{\text {Treated }}-\Delta \mathrm{H}_{\text {Control }}\right] / \Delta \mathrm{H}_{\text {Control }} \times 100
$$

Where, $\Delta \mathrm{H}_{\text {Control }}$ and $\Delta \mathrm{H}_{\text {Treated }}$ are the latent heat of fusion of control and treated samples, respectively.

\subsection{Thermogravimetric Analysis-Differential Thermal Analysis (TGA-DTA)}

A Mettler Toledo simultaneous TGA and differential thermal analyzer (DTA) was used to investigate the thermal stability of control and treated 2-AP samples. The rate of heating was $5^{\circ} \mathrm{C} / \mathrm{min}$ and samples were heated in the range of $30-400^{\circ} \mathrm{C}$ under air atmosphere.

\subsection{UV-Vis Spectroscopic Analysis}

A Shimadzu UV-2400 PC series spectrophotometer with 1 $\mathrm{cm}$ quartz cell and a slit width of $2.0 \mathrm{~nm}$ was used to obtain the UV spectra of the control and treated 2-AP samples. The spectroscopic analysis was carried out using wavelength in the range of 200-400 $\mathrm{nm}$ and methanol was used as a solvent.

\subsection{FT-IR Spectroscopy}

The FT-IR spectra were recorded on Shimadzu's Fourier transform infrared spectrometer (Japan) with the frequency range of $4000-500 \mathrm{~cm}^{-1}$. The biofield energy treated sample was divided in two parts T1 and T2 for the FT-IR analysis. 


\section{Results and Discussion}

\subsection{XRD Study}

$\mathrm{XRD}$ is a non-destructive technique that is widely used to evaluate the crystalline nature of the materials. The XRD diffractograms of control and treated samples are shown in Fig. 1. The XRD diffractogram of the control sample showed intense peaks at $2 \theta$ equal to $13.68^{\circ}, 15.10^{\circ}, 15.23^{\circ}, 19.17^{\circ}$, $19.45^{\circ}, 19.64^{\circ}, 23.68^{\circ}, 23.98^{\circ}, 25.40^{\circ}, 28.16^{\circ}, 28.37^{\circ}, 30.48^{\circ}$ and $34.56^{\circ}$. However, the treated sample showed XRD peaks at $2 \theta$ equal to $14.81^{\circ}, 15.03^{\circ}, 15.41^{\circ}, 19.03^{\circ}, 19.23^{\circ}, 21.57^{\circ}$, $23.61^{\circ}, 28.10^{\circ}, 30.47^{\circ}$, and $34.40^{\circ}$. The result showed that $2 \theta$ peak originally present at $13.68^{\circ}$ with lower intensity was shifted to $14.81^{\circ}$ in the treated sample. Additionally, the XRD peak at $15.23^{\circ}$ in control was also shifted to higher Braggs angle $15.41^{\circ}$ in the treated 2-AP sample. It was reported that increase in $2 \theta$ peak mainly occurs due to stress in the sample. Namazu et al. during their studies on sputtered gold-tin eutectic film reported that as the tensile stress increases this causes XRD peak shift to the higher angle (20) [21]. Hence, it is assumed that tensile stress might be applied in the treated sample due to biofield energy treatment that caused an increase in $2 \theta$ angle of the XRD peak as compared to the control.

The crystallite size was calculated using well-known Scherrer formula and results are reported in Fig. 2. The crystallite size of the control sample was $97.99 \mathrm{~nm}$ and it was decreased upto $91.80 \mathrm{~nm}(6.31 \%)$ in the treated sample. It was reported that the crystallite size directly influences the materials properties, and it is one of the crystallographic parameters linked with the formation of dislocations and point defects in a crystal structure [22]. Researchers have shown that magnitude of tensile stress is inversely proportional to the crystallite size [23, 24]. Schafer et al. and Schwarzbach et al. have experimentally demonstrated that increase in tensile stress causes a decrease in crystallite size of the materials $[25,26]$. It is believed that tensile stress arises due to the interactions across grain boundaries when the grain starts to coalesce. Further, the grain exerts attractive atomic forces along the grain boundaries to minimize the surface energy but are forced by adhesion to the substrate, which results in tensile stress [27]. Therefore, it is hypothesized that the biofield energy treatment might cause attractive forces in the particle/grain boundaries of treated 2AP that reduced the surface energy and increased the tensile stress. This further led to a decrease in crystallite size of the treated sample as compared to the control.

It was previously reported that nano scale particle size and small crystallite size can overcome slow diffusion rate by reducing the overall diffusion distance, and this ultimately enhances the net reaction rate [28, 29]. It is reported that the lower crystallite size can improve the reaction rate [30]. Hence, the reduced crystallite size after biofield treatment, may increase the reaction rate of 2-AP to be utilized for the synthesis of pharmaceutical compounds.
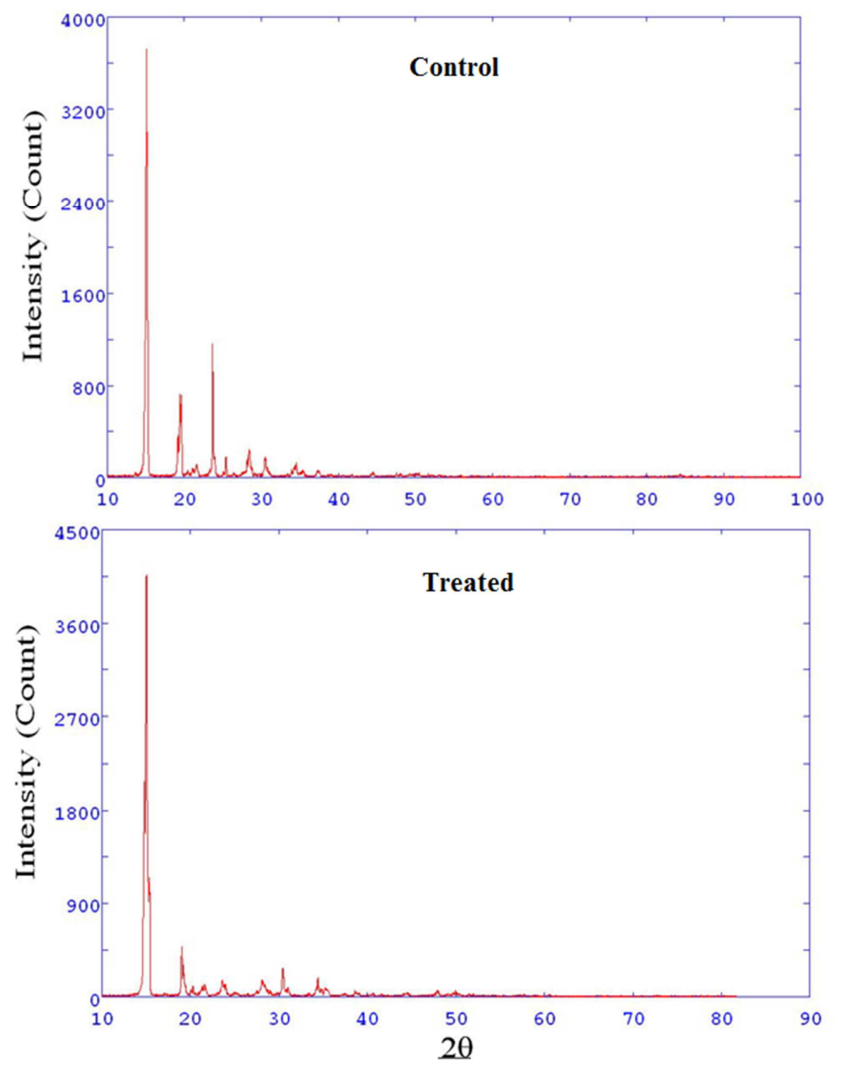

Fig. 1. XRD diffractograms of control and treated 2-aminopyridine.

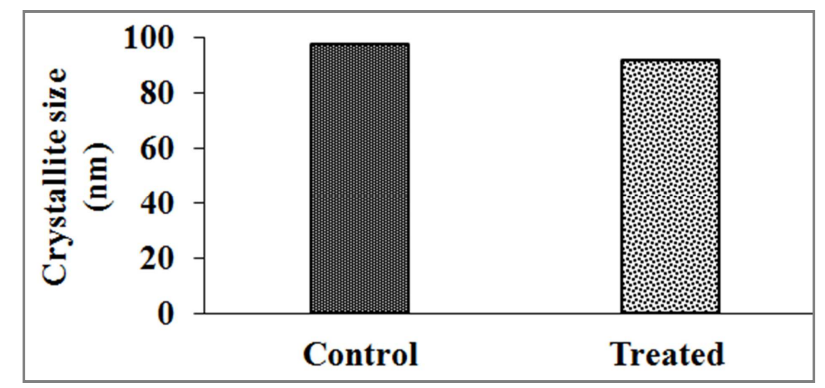

Fig. 2. Crystallite size of control and treated 2-aminopyridine.

\subsection{Differential Scanning Calorimetry}

DSC is a thermal analysis technique that is widely used for evaluation of melting temperature, glass transition, and latent heat of fusion of the materials. The DSC thermograms of control and treated samples are shown in Fig. 3. The DSC graph of the control 2-AP showed a sharp endothermic peak at $60.90^{\circ} \mathrm{C}$ that was due to melting temperature of the sample. This was well supported by the reported melting temperature of pure 2-AP [4]. However, the DSC thermogram of treated 2 -AP showed a melting endothermic peak at $61.32^{\circ} \mathrm{C}$. This suggested the increase in melting temperature of the 2-AP after biofield energy treatment. It was previously reported that the melting temperature is the best descriptor of thermal stability of the compounds [31]. Hence, it is assumed that biofield treatment had perhaps caused an increase in thermal stability of the 2-AP.

The latent heat of fusion of the control and treated sample 
were obtained from the thermograms and data are presented in Table 1. The control sample showed the latent heat of fusion of $155.99 \mathrm{~J} / \mathrm{g}$ and it was decreased slightly to 151.18 $\mathrm{J} / \mathrm{g}$ in the treated sample. The latent heat of fusion is the energy absorbed in a material during its phase change from solid to liquid. Hence, it is speculated that biofield energy treatment had perhaps alerted the stored energy in the treated sample that led to a decrease in latent heat of fusion of the treated 2-AP as compared to the control.

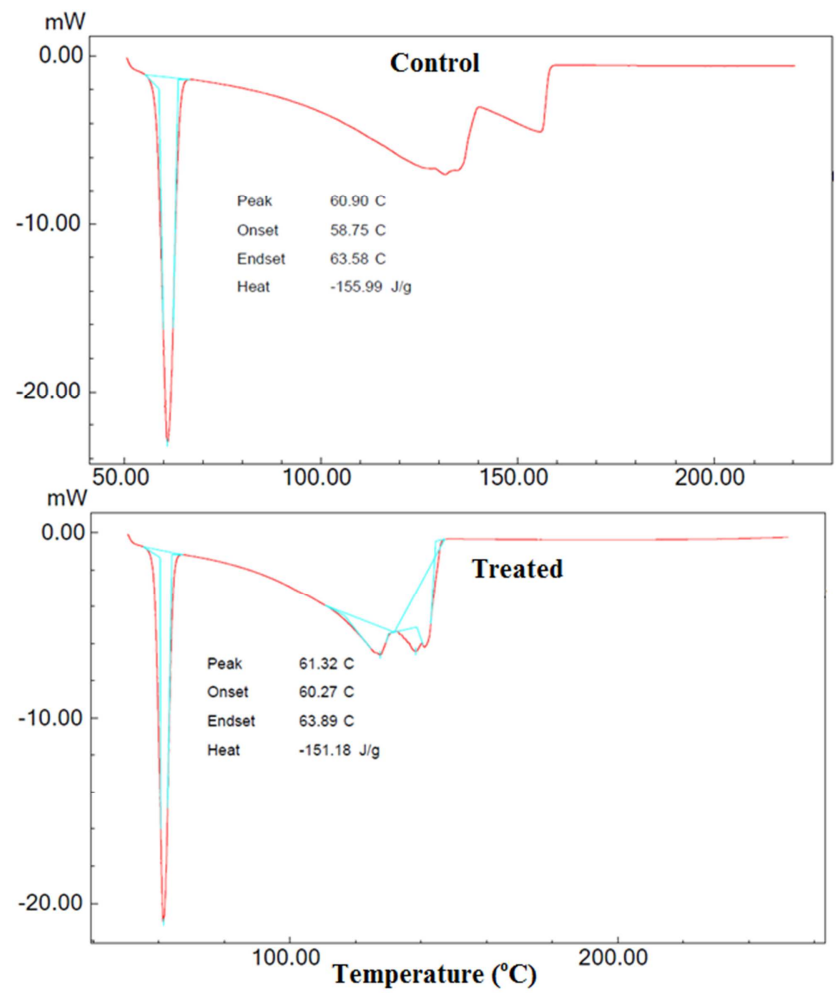

Fig. 3. DSC thermograms of control and treated 2-aminopyridine.

\subsection{TGA Analysis}

TGA is a thermal analysis technique that gives vital information about the thermal stability, oxidation, sublimation and thermal decomposition of the materials. The thermal decomposition of the control sample started at around $112^{\circ} \mathrm{C}$, and it stopped at $158^{\circ} \mathrm{C}$. Whereas, the treated sample showed thermal decomposition at around $150^{\circ} \mathrm{C}$, and it terminated at $190^{\circ} \mathrm{C}$. Both the control and treated samples lost 67.01 and $44.64 \%$, respectively from its initial weight during this process. The low weight loss of the treated 2-AP was associated with increased thermal stability of the sample as compared to the control.

DTA thermograms of the control and treated samples are presented in Fig. 4. The DTA thermogram of the control sample exhibited two endothermic transitions at $60.16^{\circ} \mathrm{C}$ and $142.98^{\circ} \mathrm{C}$. The former endothermic peak was due to melting temperature of the untreated sample. The later peak was might be due to thermal decomposition or volatilization of the control sample. Similarly, the treated sample also exhibited two endothermic peaks at $63.27^{\circ} \mathrm{C}$ and $172.50^{\circ} \mathrm{C}$.
The first endothermic peak was due to melting and the second peak was due to volatilization temperature of the treated 2-AP. The results suggested an increase in melting temperature and volatilization temperature of the treated sample as compared to the control sample. This was supported by DSC data of the samples.

The derivative thermogravimetric (DTG) analysis of the control and treated samples are shown in Fig. 4. The DTG thermogram was used to record the maximum thermal decomposition temperature $\left(\mathrm{T}_{\max }\right)$ of the samples. The DTG thermogram of the control sample showed $\mathrm{T}_{\max }$ at $132.03^{\circ} \mathrm{C}$ and it was increased significantly to $163.45^{\circ} \mathrm{C}$ in the treated sample. Additionally, the onset of thermal degradation $\left(\mathrm{T}_{\text {onset }}\right)$ of the control sample was $93.61^{\circ} \mathrm{C}$, and it was increased to $133.64^{\circ} \mathrm{C}$ in the treated 2-AP. Overall, the increase in melting temperature, volatilization temperature, $\mathrm{T}_{\max }$, and $\mathrm{T}_{\text {onset }}$ of the treated 2-AP indicated the much higher thermal stability of the sample as compared to the control. Researchers have shown that several factors contribute to thermostability of organic materials such as hydrophobicity [32], better packing, deletion or shortening of loops [33], smaller and less numerous cavities, increase surface area upon oligomerization [34], etc. Zhao et al. reported that three kinds of hydrogen bond binding sites are present in the 2-AP molecule [35]. Further, they elaborated that intermolecular hydrogen bonding is strengthened in the excited state. Therefore, it is hypothesized that biofield energy treatment improved the compactness and intermolecular hydrogen bonding in 2-AP that led to increase in thermal stability of the treated sample as compared to the control.

Table 1. Thermal analysis data of control and treated 2-aminopyridine.

\begin{tabular}{lll}
\hline Parameter & Control & Treated \\
\hline Latent heat of fusion $\Delta \mathrm{H}(\mathrm{J} / \mathrm{g})$ & 155.99 & 151.18 \\
Melting temperature $\left({ }^{\circ} \mathrm{C}\right)$ & 60.90 & 61.32 \\
$\mathrm{~T}_{\max }\left({ }^{\circ} \mathrm{C}\right)$ & 132.03 & 163.45 \\
Weight loss $(\%)$ & 67.01 & 44.64 \\
\hline
\end{tabular}

$\mathrm{T}_{\max }$ : maximum thermal decomposition temperature

\subsection{UV-visible Spectroscopy}

$\mathrm{UV}$-visible analysis was used to investigate the chemical changes in the treated 2-AP as compared to the control sample. The UV spectra of control and treated 2-AP sample are presented in Fig. 5. The UV spectrum of control 2-AP showed two absorption peaks at 233 and $296 \mathrm{~nm}$. However, the T1 sample showed absorption peaks at 234 and $298 \mathrm{~nm}$. Whereas the T2 sample exhibited the absorption peaks at 233 and $295 \mathrm{~nm}$ in the UV spectrum. Overall, the result showed no significant changes in the absorption peaks of the treated 2-AP as compared to the control sample. Hence, the result demonstrated that biofield energy treatment had perhaps no effect on the energy gap of highest occupied molecular orbital and lowest unoccupied molecular orbital (HOMOLUMO gap) [36] of the treated 2-AP sample. 

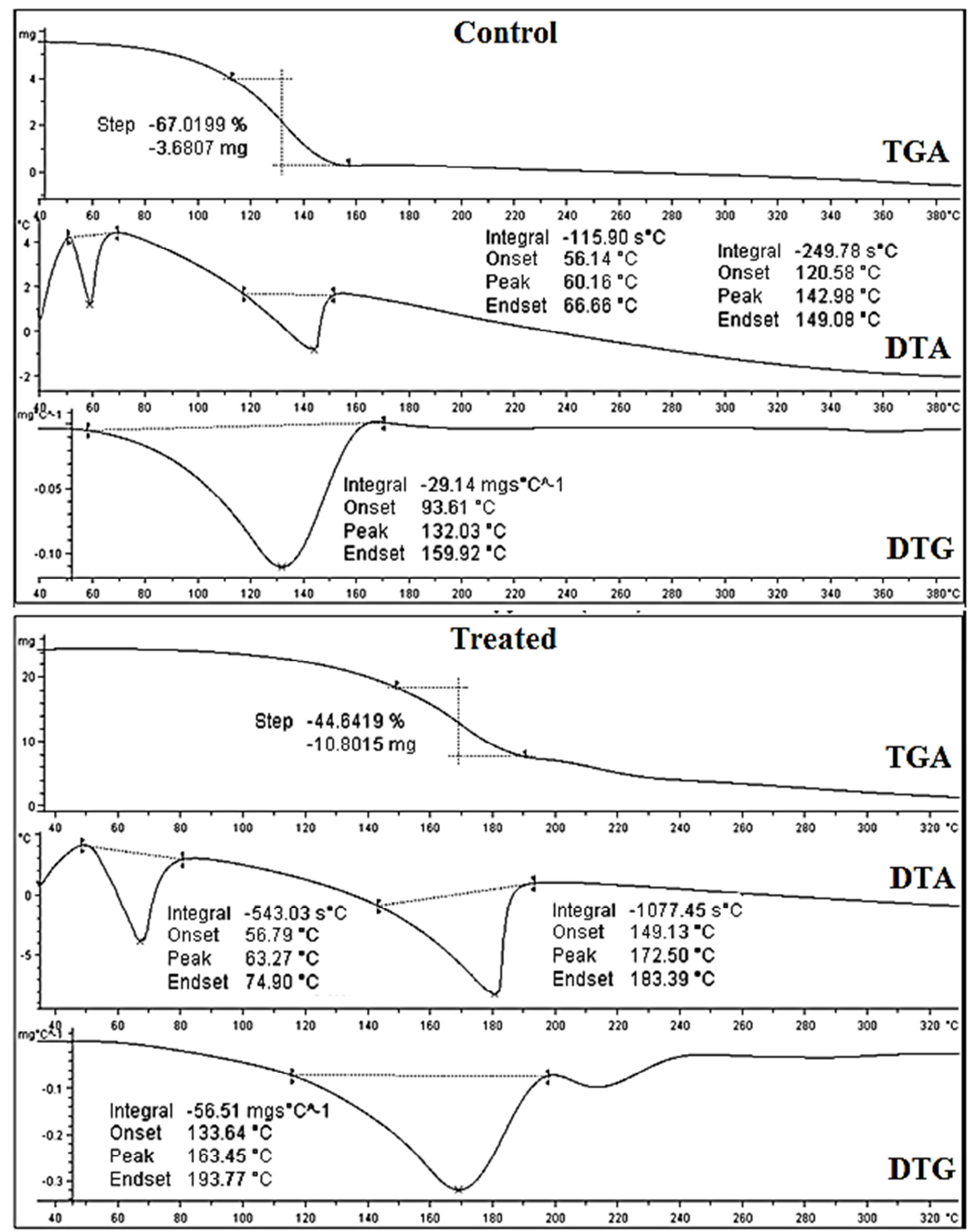

Fig. 4. TGA thermograms of control and treated 2-aminopyridine.

\subsection{FT-IR Spectroscopy}

FT-IR spectroscopy was used to elucidate the functional group changes in the sample after biofield treatment. FT-IR spectra of the control and treated 2-AP samples are presented in Fig. 6. FT-IR spectrum of the control 2-AP showed characteristic vibration peaks at 3448,3284 and $3176 \mathrm{~cm}^{-1}$ due to N-H asymmetric, N-H symmetric and N-H stretching vibrations, respectively. Whereas, in $\mathrm{T} 1$ and $\mathrm{T} 2$ these peaks were observed in the region of $3188-3444 \mathrm{~cm}^{-1}$ and $3192-$ $3452 \mathrm{~cm}^{-1}$, respectively. The vibration peaks at 2991, 2953 and $2955 \mathrm{~cm}^{-1}$ were due to $\mathrm{C}-\mathrm{H}$ stretching in the control, T1 and T2 sample, respectively. The bands at 1624 and $987 \mathrm{~cm}^{-1}$ were mainly due to the skeletal vibration of pyridine ring in the control $[37,38]$, and T1 samples. The T2 showed these stretching vibrations at 1637 and $987 \mathrm{~cm}^{-1}$ in the sample. The absorption bands in the region of 1442-1489 $\mathrm{cm}^{-1}, 1442-1487$ $\mathrm{cm}^{-1}$ and $1448-1485 \mathrm{~cm}^{-1}$ were due to asymmetrical $\mathrm{C}-\mathrm{H}$ 
stretching vibration peaks in control, T1, and T2 samples. The stretching vibration peak at $1064 \mathrm{~cm}^{-1}$ was due to $\mathrm{C}-\mathrm{N}$ stretching vibration in the control and $\mathrm{T} 2$ sample, while in $\mathrm{T} 1$ was observed at $1062 \mathrm{~cm}^{-1}$. The vibration peaks at 628-765 $\mathrm{cm}^{-1}$ were attributed to the $=\mathrm{C}-\mathrm{H}$ bending in the control, and T1 samples. Nevertheless, the T2 sample showed these vibration peaks at $628-777 \mathrm{~cm}^{-1}$. The stretching bands in the region of 520-565 $\mathrm{cm}^{-1}$ were due to out of plane ring (phenyl ring) deformation in the control and $\mathrm{T} 1$ samples. Whereas, in case of T2 sample it appeared at 522-628 $\mathrm{cm}^{-1}$. Overall the results revealed downward shifting of C-H stretching vibration $2991 \rightarrow 2955 \mathrm{~cm}^{-1}$ in the treated sample as compared to the control sample. Besides this, no significant changes were observed in FT-IR spectrum of the treated sample with respect to the control. It is presumed that biofield energy treatment had perhaps altered the force constant or bond strength of the $\mathrm{C}-\mathrm{H}$ bond in treated 2-AP as compared to the control sample.

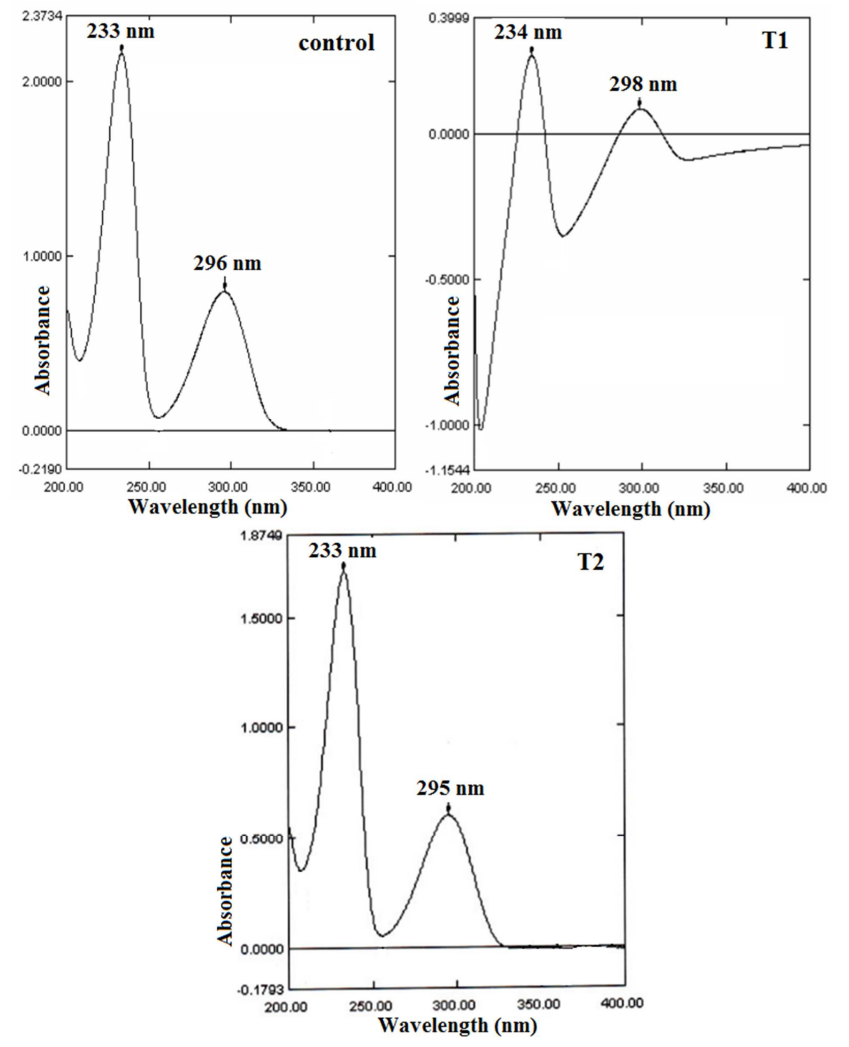

Fig. 5. UV spectra of control and treated 2-aminopyridine.

\section{Conclusions}

In summary, the results demonstrated that the biofield energy treatment has influenced the physical, thermal and spectral properties of 2-AP. The XRD study showed a decrease in crystallite size as well as an increase in Bragg's angle $(2 \theta)$ of the XRD peaks as compared to the control sample. It is speculated that biofield energy treatment may cause tensile stress in the treated 2-AP molecules that led to a shift in $2 \theta$ angle and decrease in crystallite size. The DSC and DTA exhibited the increase in melting temperature of the treated sample. However, the latent heat of fusion of the treated 2-AP was decreased as compared to the control. The biofield energy might have altered the stored internal energy in the treated sample that led to a reduction in latent heat of fusion. The TGA analysis showed an increase in onset of thermal degradation, $T_{\max }$, and reduction in weight loss of the treated 2-AP, which corroborated the high thermal stability of sample as compared to the control. The FT-IR results showed downward shifting in vibration bands of $\mathrm{C}-\mathrm{H}$ group stretching as compared to the control. Overall, the result demonstrated that smaller crystallite size and good thermal stability (more temperature stable with higher reaction rate) might improve its applicability as better intermediate for the synthesis of pharmaceutical compounds.

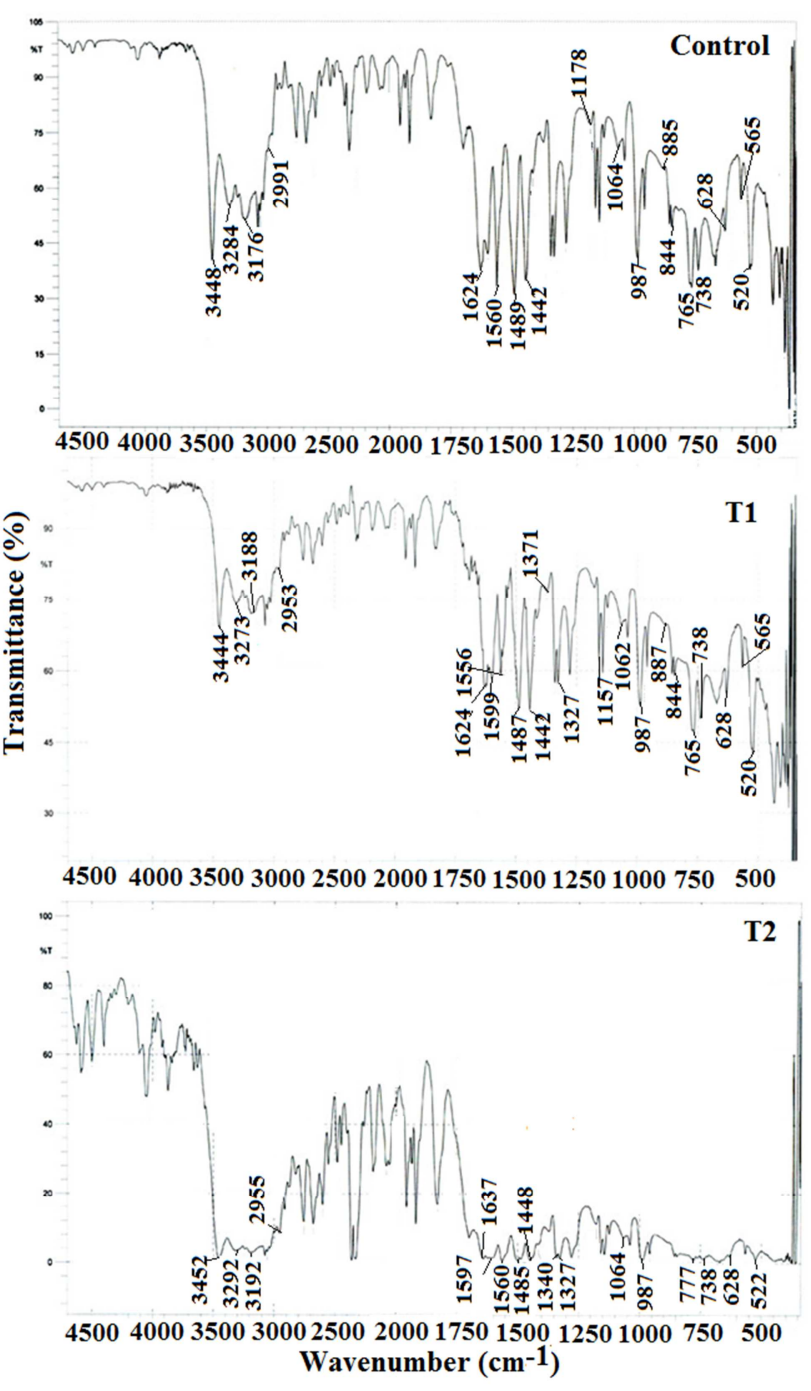

Fig. 6. FT-IR spectra of control and treated 2-aminopyridine.

\section{Abbreviations}

XRD: X-ray diffraction; DSC: Differential scanning calorimetry; TGA: Thermogravimetric analysis; FT-IR: Fourier transform infrared; UV: Ultra violet. 


\section{Acknowledgments}

The authors wish to thank all the laboratory staff of MGV Pharmacy College, Nashik for their kind assistance during handling the various instrument characterizations. The authors would also like to thank Trivedi Science, Trivedi Master Wellness and Trivedi Testimonials for their support during the work.

\section{References}

[1] Solari A, Uitdehaag B, Giuliani G, Pucci E, Taus C (2003) Aminopyridines for symptomatic treatment in multiple sclerosis. Cochrane Database Syst Rev 2: CD001330.

[2] Korenke AR, Rivey MP, Allington DR (2008) Sustainedrelease fampridine for symptomatic treatment of multiple sclerosis. Ann Pharmacother 42: 1458-1465.

[3] New Drugs: Fampridine. Australian Prescriber (34): 119-123. August 2011.

[4] https://en.wikipedia.org/wiki/2-Aminopyridine (Accessed on 12 October 2015).

[5] Brayfield A (2014) "Piroxicam". Martindale: The Complete Drug Reference. Pharmaceutical Press, London, UK.

[6] TGA Approved Terminology for Medicines, Section 1, Chemical Substances" (PDF). Therapeutic Goods Administration, Department of Health and Ageing, Australian Government. July 1999.

[7] Gonzalez Cabrera D, Douelle F, Younis Y, Feng TS, Le Manach C, et al. (2012) Structure activity relationship studies of orally active antimalarial 3,5- substituted 2-aminopyridines. J Med Chem 55: 11022-11030.

[8] Younis Y, Douelle F, Feng TS, Gonzalez Cabrera D, Le Manach C, et al. (2012) 3,5-Diaryl-2-aminopyridines as a novel class of orally active antimalarials demonstrating single dose cure in mice and clinical candidate potential. J Med Chem 55: 3479-3487.

[9] Younis Y, Douelle F, Gonzalez Cabrera D, Le Manach C, Nchinda AT, et al. (2013) Structure activity- relationship studies around the 2-amino group and pyridine core of antimalarial 3,5-diarylaminopyridines lead to a novel series of pyrazine analogues with oral in vivo activity. J Med Chem 56: 8860-8871.

[10] Dambuza N, Smith P, Evans A, Taylor D, Chibale K, et al. (2015) A pharmacokinetic study of antimalarial 3,5-diaryl-2aminopyridine derivatives. Malar Res Treat 2015: 5 Article ID 405962.

[11] Samadi A, Marco-Contelles J, Soriano E, Alvarez-Perez M, Chioua M, et al. (2010) Multipotent drugs with cholinergic and neuroprotective properties for the treatment of Alzheimer and neuronal vascular diseases. I. Synthesis, biological assessment, and molecular modeling of simple and readily available 2-aminopyridine-, and 2-chloropyridine-3,5dicarbonitriles. Bioorg Med Chem 18: 5861-5872.

[12] Singh S, Bakshi M (2000) Guidance on conduct of stress test to determine inherent stability of drugs. Pharm Technol Online 24-36.
[13] Kommanaboyina B, Rhodes CT (1999) Trends in stability testing, with emphasis on stability during distribution and storage. Drug Dev Ind Pharm 25: 857-868.

[14] Trivedi MK, Tallapragada RM, Branton A, Trivedi A, Nayak G, et al. (2015) Biofield treatment: A potential strategy for modification of physical and thermal properties of indole. $\mathrm{J}$ Environ Anal Chem 2: 152.

[15] Trivedi MK, Patil S, Shettigar H, Bairwa K, Jana S (2015) Effect of biofield treatment on spectral properties of paracetamol and piroxicam. Chem Sci J 6: 98.

[16] Trivedi MK, Nayak G, Patil S, Tallapragada RM, Mishra R (2015) Influence of biofield treatment on physicochemical properties of hydroxyethyl cellulose and hydroxypropyl cellulose. J Mol Pharm Org Process Res 3: 126.

[17] http://www.red-spirit-energy-healing.com/humanbiofield.html (Accessed on 4th September 2015).

[18] Barnes PM, Powell-Griner E, McFann K, Nahin RL (2004) Complementary and alternative medicine use among adults: United States, 2002. Semin Integr Med 2: 54-71

[19] Shinde V, Sances F, Patil S, Spence A (2012) Impact of biofield treatment on growth and yield of lettuce and tomato. Aust J Basic Appl Sci 6: 100-105.

[20] Trivedi MK, Patil S, Shettigar H, Bairwa K, Jana S (2015) Phenotypic and biotypic characterization of Klebsiella oxytoca: An impact of biofield treatment. J Microb Biochem Technol 7: 202-205.

[21] Namazu T, Takemoto H, Inoue S (2010) Tensile and creep characteristics of sputtered gold tin eutectic solder film evaluated by XRD tensile testing. Sensor Mater 22: 13-24.

[22] Ohira T, Yamamoto O (2012) Correlation between antibacterial activity and crystallite size on ceramics. Chem Eng Sci 68: 355-361.

[23] Bergman L, Nemanich RJ (1995) Raman and photoluminescence analysis of stress state and impurity distribution in diamond thin films. J Appl Phys 78: 6709-6719.

[24] Windischmann H, Epps GF, Cong Y, Collins RW (1991) Intrinsic stress in diamond films prepared by microwave plasma CVD. J Appl Phys 69: 2231.

[25] Schafer L, Jiang X, Klages CP (1991) Applications of diamond and related materials. Elsevier, Amsterdam.

[26] Schwarzbach D, Haubner R, Lux B (1994) Internal stresses in CVD diamond layers. Diamond Relat Mater 3: 757-764.

[27] Stolk RL, Buijnsters JG, Schermer JJ, Teofilov N, Sauer R, et al. (2003) The effect of nitrogen addition during flame deposition of diamond as studied by solid-state techniques. Diamond Relat Mater 12: 1322-1334.

[28] Chaudhary AL, Sheppard DA, Paskevicius M, Webb CJ, Gray $\mathrm{EM}$, et al. (2014) $\mathrm{Mg}_{2} \mathrm{Si}$ nanoparticle synthesis for high pressure hydrogenation. J Phys Chem C 118: 1240-1247.

[29] Chaudhary AL, Sheppard DA, Paskevicius M, Saunders M, Buckley CE (2014) Mechanochemical synthesis of amorphous silicon nanoparticles. R Soc Chem Adv 4: 21979-21983.

[30] Chaudhary AL, Sheppard DA, Paskevicius M, Pistidda, C, Dornheim M, et al. (2015) Reaction kinetic behaviour with relation to crystallite/grain size dependency in the $\mathrm{Mg}-\mathrm{Si}-\mathrm{H}$ system. Acta Mater 95: 244-253. 
[31] Kumar S, Tsai CJ, Nussinov R (2000) Factors enhancing protein thermostability. Protein Eng 13: 179-191.

[32] Haney P, Konisky J, Koretke KK, Luthey Schulten Z, Wolynes PG et al. (1997) Structural basis for thermostability and identification of potential active site residues for adenylate kinases from the archaeal genus Methanococcus. Proteins 28: 117-130.

[33] Russel RJ, Ferguson JM, Haugh DW, Danson MJ, Taylor GL (1997) The crystal structure of citrate synthase from the hyperthermophilic archaeon pyrococcus furiosus at $1.9 \mathrm{~A}$ resolution. Biochemistry 36: 9983-9994.

[34] Salminen T, Teplyakov A, Kankare J, Cooperman BS, Lahti $\mathrm{R}$, et al. (1996) An unusual route to thermostability disclosed by the comparison of Thermus thermophilus and Escherichia coli inorganic pyrophosphatases. Protein Sci 5: 1014-1025.
[35] Zhao J, Song P, Cui Y, Liu X, Sun S, et al. (2014) Effects of hydrogen bond on 2-aminopyridine and its derivatives complexes in methanol solvent. Spectrochim Acta A Mol Biomol Spectrosc 131: 282-287.

[36] Pavia DL, Lampman GM, Kriz GS (2001) Introduction to spectroscopy. (3rdedn), Thomson Learning, Singapore.

[37] Khan TA, Rather MA, Jahan N, Varkey SP, Shakir M (1997) Synthesis and characterization of bis(Macrocyclic) complexes based on the 13-membered pentaaza unit. Synth React Inorg Met Org Chem 27: 843-854.

[38] Mashaly MM, Abd-Elwahab ZH, Faheim AA (2004) Preparation, spectral characterization and antimicrobial activities of schiff base complexes derived from 4aminoantipyrine. Mixed ligand complexes with 2aminopyridine, 8-hydroxyquinoline and oxalic acid and their pyrolytical products. J Chin Chem Soc 51: 901-915. 